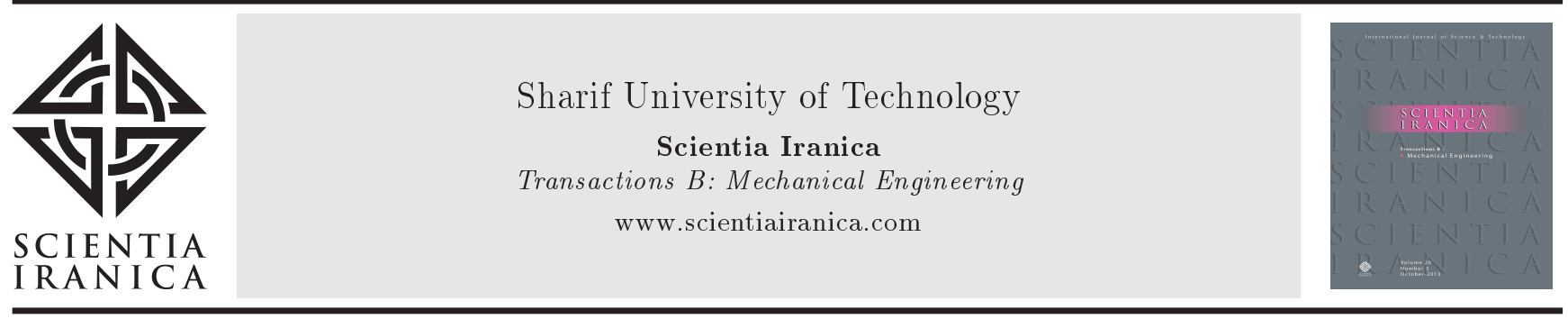

\title{
Discrete mass modeling for dynamic response of buildings in the vicinity of railway tracks due to train-induced ground vibrations
}

\author{
M.A. Rezvani*, M. Esmaeili and M.M. Feizi \\ School of Railway Engineering, Iran University of Science and Technology, Narmak, Tehran, P.O. Box 16846-13114, Iran.
}

Received 28 April 2015; received in revised form 20 February 2016; accepted 2 July 2016

\section{KEYWORDS \\ Dynamic response; \\ Ground borne \\ vibrations; \\ Structural vibration; \\ Discrete mass \\ modeling; \\ Vibration annoyance; \\ Railway track.}

\begin{abstract}
Annoying vibration waves generated by passing trains highlight the necessity for the assessment of the effects of railways on their environment. Dynamics of structures close to railway tracks is amongst such important issues. Contrary to the past studies, this article proposes a modeling method that is totally based on the idea of discrete masses. It considers three major parts as the accomplices causing undesirable oscillations including the track, the ground bed, and the structure in the vicinity of the track. The ground bed is considered as an elastic half space subdivided into discrete masses. It facilitates modeling for the track systems that may include any deliberate discontinuity, such as voids and trenches, in the ground bed that supports the railway track. Such discontinuities arise from engineering perception and are useful in controlling the spread of noise and vibrations. A "MATLAB" based computer program is written to solve the motion equations in the time domain. The proposed method provides flexibility in modeling. Variety of track loading and wave propagation scenarios can be simulated without the need to rebuild the model. This method can be practically used when seeking remedies for controlling the levels of unwanted vibrations in the structures.
\end{abstract}

(C) 2017 Sharif University of Technology. All rights reserved.

\section{Introduction}

Railway transportation is amongst the most popular modes of transport in many countries around the globe. There is an unstoppable growth of railways in its many sub-branches including the freight department, the rapid transit, and the intercity modes. This undeniable fact of life also highlights the necessity for the assessment of the effects of railways on their surrounding environment. Environmental vibrations and the noise

*. Corresponding author. Tel.: +9821 r7240540; Fax: +982177451568

E-mail addresses: rezvani_ma@iust.ac.ir (M.A. Rezvani); m_esmaeili@iust.ac.ir (M. Esmaeili); mmfeizi@yahoo.com (M.M. Feizi) generated from the passing trains are amid such issues that are of prime concern to the railway operators, the environmental engineers, the city planners, etc. It may take some time for the deteriorating effects of the unwanted vibrations to appear on the nearby buildings. But, it can have serious effects on normality in the laboratories, hospitals, historical places, etc. that are located near the railway tracks. Abnormal vibrations can cause damages to the sensitive equipment inside the buildings. It can severely disturb the peace of the occupants of such buildings.

The issue of vibration waves that can be generated by the passing trains is a subject that needs to be thought of during the design stages and before the track laying starts. In an effort for attenuating undesirable oscillations, the underground metro lines, the rapid 
transit tracks, and the freight lines are of prime importance. Controlling the levels of ground-borne vibrations is also important during the operation stages and when the fleets are at service.

There can also be trouble when dealing with intercity railway tracks. In rapid rail transit tracks, very often, the speed of travel of the rolling stock is higher than the speed of wave propagation in the ground. Such a condition is capable of causing severe increase in the levels of ground-borne vibrations at the surface [1]. Such a phenomenon was reported in Sweden in 1997. It forced the railway operators to lower the speed of travel for the high-speed X2000 fleet [2]. Additionally, the study of the effect of different axle loads and different travel speeds was also warranted by the researchers. Moreover, as a result of the stance of METRO in public transportation, there have been many studies concerned with the issue of vibration wave propagation through the ground. Jones and Hunt [3] studied the effect of void on the interactions between the earth and tunnels through the ground-borne vibrations. They uncoupled the individual matching nodes at the tunnel-soil interface in order to stop the transfer of force. Voids were used in order to prevent the transfer of undesirable forces. There are many standards and regulations that provide analytical and practical information concerned with the environmental effects and the evaluation of the vibrations generated by the passing trains on the nearby structures. As an example, FTA-VA-90-1003-06 [4] provides general data to evaluate vibrations caused by different means of transport. In such documents, there are also provisions for some correction factors to include the effects of the rail corrugations, wheel flat, etc. BS 6742:1992 standard [5] is concerned with human disturbance under continuous vibrations. It has produced the Root Mean Square (RMS) charts for the accelerations that are associated with the weighted frequency of such vibrations. ISO14837 standard [6] provides all parameters needed in order to properly predict the vibrations that can be generated by moving trains. DIN 4150-3 standard document [7] is concerned with identifying the threshold for the deterioration of structures against maximum speed of wave propagation in the foundation and the upper floors of buildings. It covers three types of structures including the residential, industrial-commercial, and historical structures.

The usual methods in studying the issue of wave propagation by moving trains are the empirical methods, the numerical simulations, and/or the field measurements. The numerical methods for wave propagation through the ground are generally divided into the continuous mass and the limited discrete mass models. The continuous mass method of solution mainly involves using the Finite Elements Method
(FEM) and the Boundary Element Method (BEM). Mohammadi and Karabalis [8] and Yang and Hung [9] reported many studies concerned with the dynamic interaction of the structure and the soil. Also, the issue of the track stability and propagation of Rayleigh wave along the track, especially through the soft soil was studied by Estorff et al. [10] and Bode et al. [11]. The finite-element method has also been used for the modeling of other related issues such as the wave propagation barriers. However, the boundary element methods have limited modeling applications in case of complicated geometries and also in dealing with the material contents with non-linear properties. Therefore, Adam et al. [12] and O'Brien and Rizos [13] made serious attempts in order to establish methods that are based on the combination of FEM and BEM methods. Hall [14] used the linear elastic two-dimensional and three-dimensional finite-element models of wave propagation due to train motion. He then compared the results with the field measurements. The analyses were performed in the time and frequency domains. He concluded that it is possible to use the two-dimensional models in order to study the ground vibrations. However, he suggested that in order to obtain more accurate results, the use of the threedimensional models is more promising.

Amongst the other studies in this domain are those concerned with the limited use of the discrete mass models. Such a vision for solving the issue was started in the domain of the interaction between the soil and the foundation in studying the track/train interactions. The same modeling style has been used by many researchers. In studying the issue of the interaction between the structural foundation and the elastic half space, many models were proposed by Lysmer and Richart [15] and also by Whitman and Richart [16]. Lysmer and Richart [15] showed that the vertical vibrations of a circular solid object with radius $r_{o}$ leaning on the elastic half space can comfortably be simulated by mass-spring-dashpot model if the proper spring and damping coefficients are selected. These researchers used analytical formulas from the elastic halfspace theorem in order to calculate such coefficients. By using a two-dimensional model with five frequencyindependent parameters, Wolf $[17,18]$ simulated the dynamic impedance functions of a solid disk resting on an elastic half space. Jean et al. [19] also used a threedimensional model with ten frequency-independent parameters for the simulation of a rigid foundation with horizontal, vertical, rocking, and torsion motions. Wu and Chen [20] also used a combination of mass-springdashpot models for the simulation of a foundation that was in part or totally embedded inside a uniform elastic half space. There is also a study reported by Chen and Shi [21] that is concerned with the torsional oscillations of foundation modeled as lumped masses. 
They also presented an optimized equivalent model using mass, spring, and dashpot components for the vertical vibrations of foundation connected to elastic half space [22]. They outlined that a proper definition for the stiffness, damping and equivalent masses is very effective in the accuracy of this type of modeling. However, some available models emphasize many more vital parameters that can influence the final results. It needs to be reminded that none of the past studies has considered the soil and the structure totally as discrete masses. Solving such problems has always relied on continues mass modeling methods or the field measurements. Occasionally, part of the system was also modeled as the discrete masses.

The solution procedure in this research includes the consideration of three major parts as the accomplices in causing undesirable oscillations. The first part is the location where the track is loaded. It is a medium that includes the rail and its substructures including the ballast and sleepers. There is only one degree of freedom assigned to such components, and it coincides with the direction of the track load. The second part is the soil or the elastic half space. With the assumption of discrete masses, the elastic half space is further divided into subelements. Each of these subelements holds three degrees of freedom including translations in the horizontal and vertical directions and rotation around the horizontal axis. Such subdividing of the elastic half space into discrete elements is a major proposition in this research. It paves the way for the proper and more accurate simulation of the wave propagation through the ground. The optimized dimensions of the elastic half space and the associated subelements need to be calculated based on sensitivity analysis in a repetitive procedure. The connection between the elastic half space subelements is provided by adding the compressive and frictional contacts both in vertical and horizontal directions. There are stiffness and damping coefficients associated with each compressive and frictional contact. In order to prevent the return and interference of the vibration waves, the circumferential boundaries of the elastic half space are blocked by adding the dashpot elements (Kuhlemeyer and Lysmer [23]). The third main part is a structure in the vicinity of the track. Such a structure is represented by a building for the purposes of this research. The foundation for such a structure is modeled in the elastic half space by assuming the vertical, horizontal, and the rotational degrees of freedom. The structure is considered as frames that consist of the beam elements. Each node in the structure carries three degrees of freedom including two in-plane translations and one rotation.

Eventually, the global mass, stiffness, and damping matrices, in addition to the excitation vector, form the system motion equations that need to be solved simultaneously in the time domain. A computer program is written that is in the "MATLAB" environment. It takes in the system specifications and forms its idealization matrices. It then forms the coupled system motion equations. At this stage, the computer program holds a model with a large number of subelements that represent the track loading, the ground bed, and the nearby building. It also holds some parameters that correspond to the properties of the individual subelements. There is also the provision for altering these parameters. Therefore, one has the option to adapt the program to the desired mechanical and geometrical specifications and the material content of choice. Consequently, variety of track loading and wave propagation scenarios can be simulated without the need to rebuild the model. Such flexibility in modeling is considered as a major difference and an advantage of the present method in comparison with the other available methods. The output from the computer program is the dynamic response of the structure in as many points as desired. It includes the displacement, velocity, and acceleration of the selected points.

Another point in favor of the proposed method and its programming style is the ease in processing different scenarios under variety of input data without the need to reconfigure the model. On the contrary, in the other available methods that are totally or in part based on the finite-element modeling, in order to change the dimensions of the model and its subelements, one needs to repeat the modeling procedures from scratch. This research also offers the sensitivity analysis in order to determine the degree of influence of the axle load and the fleet speed of travel on the vibrations in different floors of the structure.

\section{The system motion equations}

The elements and structure of the proposed model based on the assumption of discrete masses are discussed in this section. This model contains three main components including the rail and its infrastructure, the ground, and the nearby building. The corresponding motion equations are written with the assumption of in-plane motions. The motion equations need to include the track superstructure as the location for applying the axle load, the ground as the wave propagation medium, and the nearby building as the recipient of the oscillations. The oscillation waves are generated by the wheel impact loads. A schematic of the model is presented in Figure 1. The selected elastic half space is discretely divided into smaller subelements that form a grid of soil elements. A lumped mass is associated with each one of these subelements. Vibration waves, including the shear waves, the compressive waves, and mainly the Rayleigh 


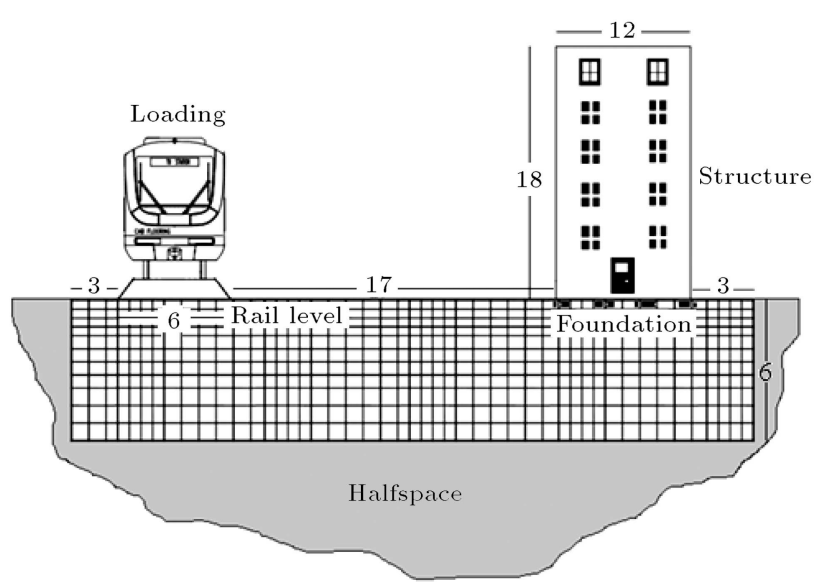

Figure 1. The schematic of the model including the vehicle and the track, the elastic half space, and the building in the vicinity of the railway track (all dimensions are in meter).

waves, depending on the level of contained energy, are transmitted to certain dimensions of the soil [24].

\subsection{Specifications of the ballasted track elements}

The ballasted railway track includes the rail and ballast. Since the vertical load is the dominant load at the wheel/rail contact point, it is assumed that all track elements contain vertical degree of freedom. The motion of all such elements is limited to the direction of the applied load. The selected rail profile is the popular UIC60 type. Combination of the two rails is considered as lumped mass for the modeling purposes. This is consistent with the vertical loading of the track by the wheels. It is assumed that there is a vibration absorbing pad between the rail and sleepers with stiffness of $K_{p}$ and damping of $C_{p}$. The connection between the sleeper of mass of $m_{s}$ and the layer of substructure is made by the pyramid ballast model that was proposed by Ahlbeck et al. [25].

In this model, it is assumed that the distribution of the load transmitted from the sleepers to the ballast is of a pyramid shape. Distribution of the stresses in this pyramid is uniform. There are no stresses outside the boundaries of this pyramid. The angular distribution of the stresses in the pyramid depends on the Poison's ratio. Therefore, the effective ballast zone underneath each sleeper can be depicted as in Figure 2, redrawn from Zhai et al. [26]. Consequently, the mass of the ballast that takes part in receiving the wheel load can be calculated as in Eq. (1):

$$
M_{b}^{\prime}=\rho_{b} h_{b}\left[l_{e} l_{b}+\left(l_{b}+l_{e}\right) h_{b} \operatorname{tg} \alpha+\frac{4}{3} h_{b}^{2} t g^{2} \alpha\right] .
$$

In this equation, $M_{b}^{\prime}$ is the mass of the ballast, $\rho_{b}$ is the ballast density, $h_{b}$ is the ballast thickness, $l_{e}$ is the effective length of the half sleeper support zone, $l_{b}$ is

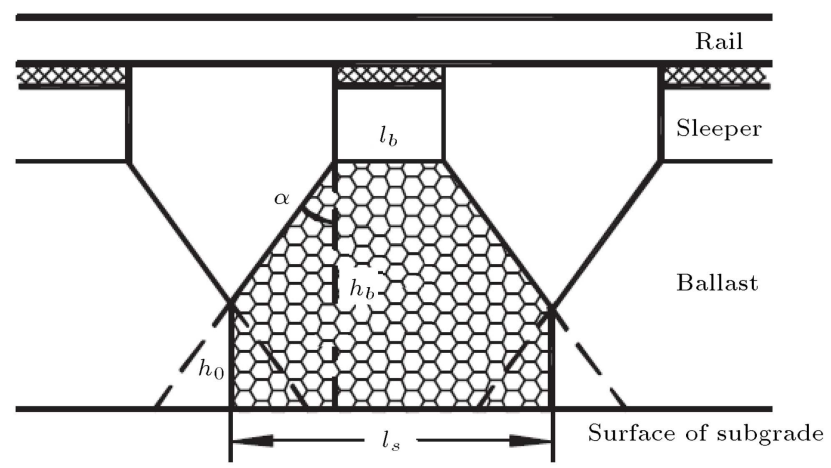

Figure 2. The domain and the effective mass of the ballast underneath a sleeper [26].

the width of the sleeper, and $\alpha$ is the angle for stress distribution in the ballast. Stiffness of the ballast layer is calculated according to Eq. (2):

$$
K_{b}^{\prime}=\frac{2\left(l_{e}-l_{b}\right) \operatorname{tg} \alpha}{\ln \left[\left(\frac{l_{e}}{l_{b}}\right) \cdot\left(l_{b}+2 h_{b} \operatorname{tg} \alpha\right) /\left(l_{e}+2 h_{b} \operatorname{tg} \alpha\right)\right]} E_{b},
$$

where $K_{b}^{\prime}$ is the ballast stiffness and $E_{b}$ is the ballast modulus of elasticity.

Development of the above equations is with the assumption of a large distribution angle $\left(\alpha=35^{\circ}[26]\right)$. In other words, there is no overlap between the adjacent pyramids. Since overlapping usually happens between the masses of the ballast; in this case, the equations related to the stiffness and mass of the ballast need to be modified [26]. Therefore, the effective ballast mass can be represented as the dashed zone in Figure 2.

In this model, the height of the two overlapping cones $\left(h_{0}\right)$ can be presented as in Eq. (3):

$$
h_{0}=h_{b}-\frac{l_{s}-l_{b}}{2 \tan \alpha},
$$

where $l_{s}$ is the distance between the neutral axes of the sleepers. The dynamic mass of the ballast $\left(M_{b}\right)$ can be calculated according to Eq. (4):

$$
\begin{aligned}
M_{b}=\rho_{b}[ & l_{b} h_{b}+\left(l_{e}+h_{b} \tan \alpha\right)+l_{e}\left(h_{b}^{2}-h_{0}^{2}\right) \tan \alpha \\
& \left.+\frac{4}{3}\left(h_{b}^{3}+h_{0}^{3}\right) \tan \alpha\right] .
\end{aligned}
$$

The stiffness of the ballast zone is calculated by considering the combination of the two zones in series according to the following equations:

$$
\begin{aligned}
K_{b} & =\frac{K_{b 1} K_{b 2}}{K_{b 1}+K_{b 2}}, \\
K_{b 1} & =\frac{2\left(l_{e}-l_{b}\right) \tan \alpha}{\ln \left[\left(l_{e} l_{s}\right) /\left(l_{b}\left(l_{e}+l_{s}-l_{b}\right)\right)\right]} E_{b}, \\
K_{b 2} & =\frac{l_{s}\left(l_{s}-l_{b}+2 l_{e}+2 h_{b} \tan \alpha\right) \tan \alpha}{l_{b}-l_{s}+2 h_{b} \tan \alpha} .
\end{aligned}
$$


Table 1. The rail track specifications [26].

\begin{tabular}{lccc}
\hline \multicolumn{1}{c}{ The parameter } & Sy mbol & Unit & Quantity (per rail) \\
\hline Rail modulus of elasticity & $E$ & $\mathrm{~N} / \mathrm{m}^{2}$ & $2.059 \times 10^{11}$ \\
Mass per unit length of single rail & $m_{r} / 2$ & $\mathrm{~kg} / \mathrm{m}$ & 60.64 \\
Mass of half sleeper & $M_{s} / 2$ & $\mathrm{~kg}$ & 125.5 \\
Stiffness of rail pad & $K_{p}$ & $\mathrm{~N} / \mathrm{m}$ & $6.5 \times 10^{7}$ \\
Damping of rail pad & $C_{p}$ & $\mathrm{Ns} / \mathrm{m}$ & $7.5 \times 10^{4}$ \\
Distance between sleepers & $l_{s}$ & $\mathrm{~m}$ & 0.545 \\
The effective length of half sleeper & $l_{e}$ & $\mathrm{~m}$ & 0.95 \\
Sleeper width & $l_{b}$ & $\mathrm{~m}$ & 0.273 \\
Ballast density & $\rho_{b}$ & $\mathrm{~kg} / \mathrm{m}^{3}$ & $1.8 \times 10^{3}$ \\
Ballast modulus of elasticity & $E_{b}$ & $\mathrm{~Pa}$ & $1.1 \times 10^{8}$ \\
Ballast damping & $C_{b}$ & $\mathrm{Ns} / \mathrm{m}$ & $5.88 \times 10^{4}$ \\
Ballast stress distribution angle & $\alpha$ & $\mathrm{Degrees}$ & 35 \\
Ballast thickness & $h_{b}$ & $\mathrm{~m}$ & 0.45 \\
\hline
\end{tabular}

All the parameters required to calculate the mass, stiffness, and damping for the track elements are presented in Table 1. Following the specified parameters, the mass matrix for the track can be obtained according to Eq. (8):

$$
M_{\mathrm{track}}=\operatorname{diag}\left[m_{r} M_{s} M_{b}\right]
$$

where $m_{r}, M_{s}$, and $M_{b}$ represent the rail, soil, and ballast masses, respectively.

$K_{y t}$ is the stiffness matrix for the track elements in the vertical direction. It is already highlighted that the track degree of freedom is in vertical " $y$ " direction. Therefore, the corresponding stiffness matrix of dimension $3 \times 3$ can be written only in such a direction as in Eq. (9):

$$
K_{y t}=\left[\begin{array}{ccc}
2 K_{p} & -2 K_{p} & 0 \\
-2 K_{p} & K_{p}+K_{b} & -K_{b} \\
0 & -K_{b} & K_{b}+K_{c}
\end{array}\right]
$$

where $K_{c}=\beta K_{v}$ represents the connection between the railway track and the elastic half space. $K_{v}$ is the vertical stiffness of the elastic half space, and $\beta$ is the modification factor that depends on the combined properties of the ground and track ballast. For the purposes of this research, $\beta$ is equal to 3 for calculating the soil stiffness matrix.

\subsection{Specifications of the ground (as the transfer medium)}

Modeling of the soil is based on the elastic half-space simulation that was presented by Bycroft [27]. In order for such a cubic element to be capable of transmitting the energy waves generated by the passing trains, it needs to have at least one vertical, one horizontal, and one rotational degrees of freedom. Therefore, there are three stiffness coefficients and three damping coefficients that need to be assigned to each element compatible with its degrees of freedom. In addition, the stiffness and coulomb damping coefficients in the vertical and horizontal directions are also considered for each element $[28,29]$. A dynamic idealization of the whole model is presented in Figure 3 with a detailed view of a sample elastic half-space subelement and its connections that is presented in Figure 4.

The presence of the friction and torsion elements facilitates the inclusion of the elliptic motion of the Rayleigh wave in the model. By doing so, it becomes feasible to observe the horizontal motion in the soil elements upon application of the vertical loads on the ground surface. The proper sizes for these elements are calculated by using the relations presented in Table 2 .

Coefficients $k_{i}, k_{j}, c_{i}$, and $c_{j}$ are constants with the values oscillating between zero and one. They are all equal to 0.5 throughout this modeling. The stiffness and damping relations in Table 2 are for a circular element. Therefore, it is required to find their equivalents for the rectangular elements. Equivalent $r_{o}$ for a circular element of sizes $2 b \times 2 l$ with the thickness of 1 meter is also given in Table 2 . The horizontal, vertical, and torsional stiffness and damping coefficients and the associated friction coefficients are also available in Table 2. In this table, $V_{s}$ and $G$ are the speed of propagation of the shear wave and the elastic half-space modulus, respectively. Also, $A_{v}$ and $A_{h}$ are the contact area between the neighboring soil subelements in the vertical and horizontal directions, respectively.

With the assumption of the elastic half space and also for modeling the ground element, a volume of soil that actively participates in wave propagation is divided into smaller cubic subelements. The corresponding dimensions include " $2 l$ " in length, " $2 b$ " in width, and " $w$ " in thickness.

Noticing the assumption of in-plane strains, the thickness of 1 meter for the subelements is assumed. Following such dimensions, the rotational inertia is equal to $I_{\theta}=\frac{1}{3} M\left(l^{2}+b^{2}\right)$. Also, the horizontal and 


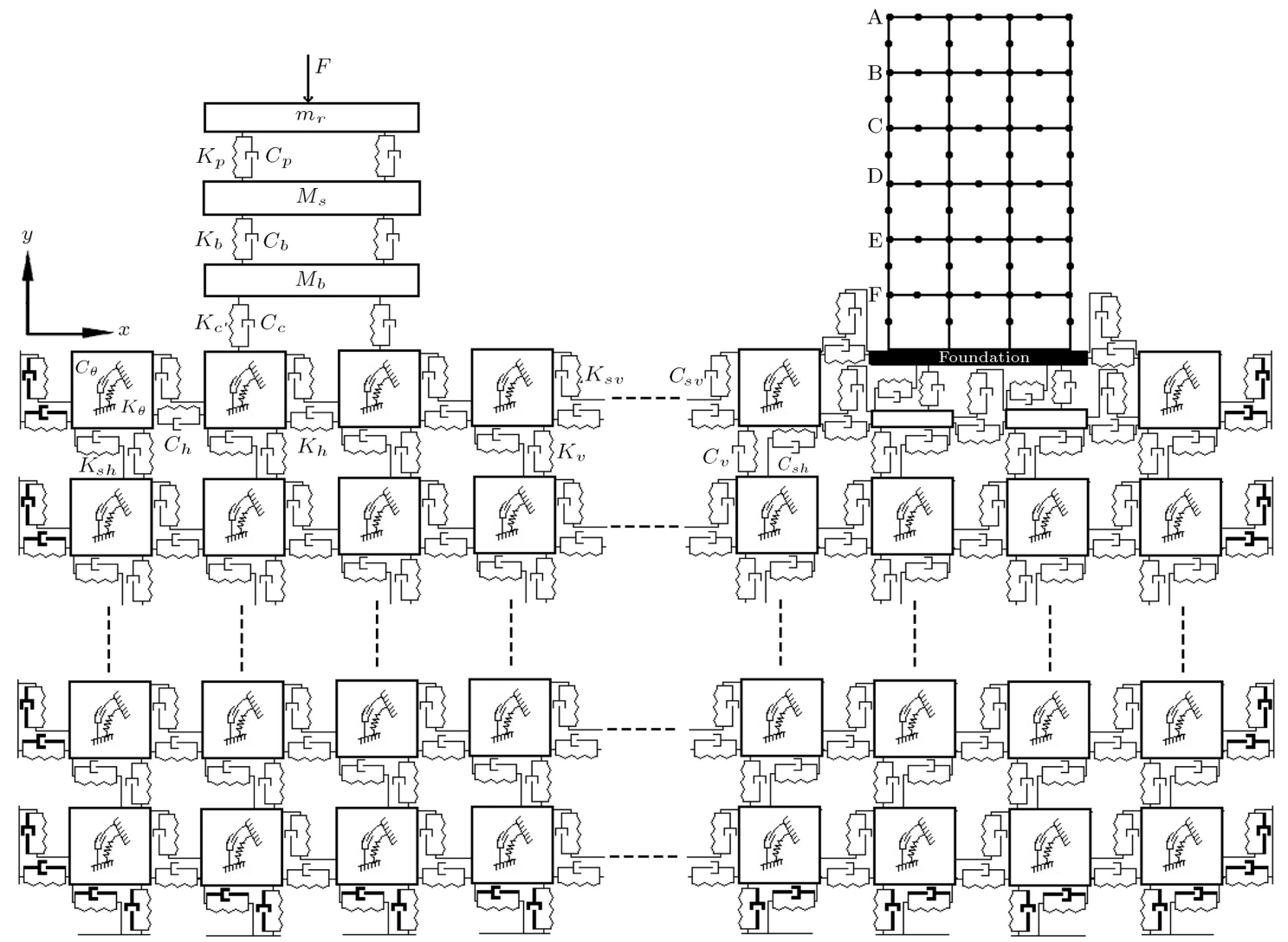

Figure 3. Dynamic idealization of the model.

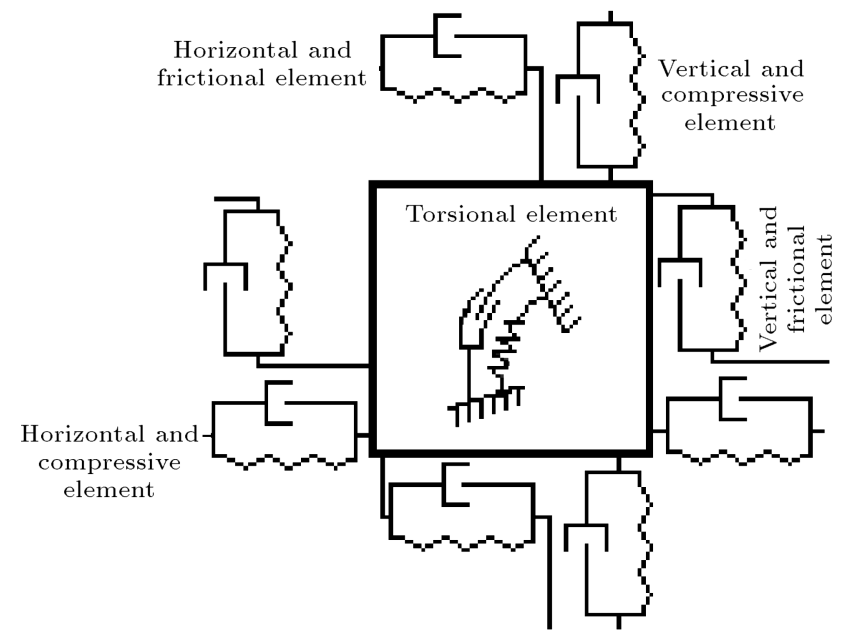

Figure 4. Detailed view of a typical elastic half-space sub-element and its connections.

vertical contact areas $A_{v}, A_{h}$, and the mass " $M$ " of each subelement are calculated as in Eq. (10):

$$
\begin{aligned}
& A_{v}=2 l \times w=2 l, \quad A_{h}=2 b \times w=2 b, \\
& M=4 \rho \times l \times b .
\end{aligned}
$$

" $\rho$ " refers to the material density in the subelement.

Using such defined parameters, mass matrix, $M_{\text {soil }}$, and moment of inertia, $J_{\text {soil }}$, for the soil can be defined as follows:

$$
\begin{aligned}
& M_{\text {soil }}=\operatorname{diag}\left[M_{11} M_{12} \cdots M_{i j} \cdots M_{m n}\right], \\
& J_{\text {soil }}=\operatorname{diag}\left[J_{11} J_{12} \cdots J_{i j} \cdots J_{m n}\right] .
\end{aligned}
$$

To tidy up the solution procedure, it makes sense to assume that the combination of the discrete subelements of the elastic half space can form a planar matrix of size $(m \times n)$. Then, in such a matrix subscript " $"$ " represents the row number, and subscript " $j$ " represents the column number for the position of the specific elements in the matrix. $K_{x s}$ is the soil stiffness along horizontal " $x$ " direction. For the ease of programming, index " $p$ " is associated with each soil subelement $(i, j)$. " $p$ " starts from number 1 that is associated with subelement $(1,1)$ and rises to cover all the subelements including element $(m, n)$. " $n_{1}$ " is the number of the soil subelement that is near the surface. As a result of the presence of the embedded structure foundation, the number of the soil subelements in different depths of the ground is not necessarily the same. " $n_{j}$ " is the number of the soil subelements in row number " $j$ ". " $j$ " varies from 1 to $m$ :

$$
\begin{aligned}
& K_{x s}(p, p+1)=-K_{h}, \quad K_{x s}(p+1, p)=-K_{h}, \\
& K_{x s}\left(p, p+n_{j}\right)=-K_{s h}, \\
& K_{x s}\left(p+n_{j}, p\right)=-K_{s h}, \quad \text { for } \quad i \leq m-1,
\end{aligned}
$$


Table 2. The flexibility and damping specifications of the ground.

\begin{tabular}{|c|c|c|c|}
\hline The parameter & Symbol & Unit & Ref. \\
\hline The vertical spring stiffness for a circle with radius $r_{o}$ & $K_{v}=\frac{4 G r_{0}}{1-v}$ & $\mathrm{~N} / \mathrm{m}$ & Hall $[28]$ \\
\hline The vertical damping coefficient for an element of area $A_{v}$ & $C_{v}=\rho V_{s} A_{v}$ & $\mathrm{Ns} / \mathrm{m}$ & Kramer [29] \\
\hline The horizontal spring coefficient for a circle of radius $r_{o}$ & $K_{h}=\frac{32(1-v)}{7-8 v} G r_{0}$ & $\mathrm{~N} / \mathrm{m}$ & Hall $[28]$ \\
\hline The horizontal damping coefficient for an element of area $A_{h}$ & $C_{h}=\rho V A_{h}$ & $\mathrm{Ns} / \mathrm{m}$ & Kramer [29] \\
\hline The torsion spring coefficient for a circle with radius $r_{o}$ & $K_{\theta}=\frac{8 G r_{0}^{3}}{3(1-v)}$ & $\mathrm{N} / \mathrm{rad}$ & Hall [28] \\
\hline The torsion damping for a circle with radius $r_{o}$ & $C_{\theta}=\frac{0.8 r_{0}^{4} \sqrt{G \rho}}{(1-\nu)\left(1+B_{\theta}\right)}$ & $\mathrm{Ns} / \mathrm{rad}$ & Hall $[28]$ \\
\hline The torsional mass ratio for a circle of radius $r_{o}$ & $B_{\theta}=\frac{3(1-v)}{8} \frac{I_{\theta}}{r_{0}^{5}}$ & & Hall $[28]$ \\
\hline $\begin{array}{l}\text { The equivalent radius for a rectangle of dimensions } \\
2 b \times 2 l \text { in sliding (horizontal) and vertical vibrations }\end{array}$ & $r_{0}=\sqrt{\frac{4 l b}{\pi}}$ & $\mathrm{m}$ & $\begin{array}{l}\text { Whitman and } \\
\text { Richart [16] }\end{array}$ \\
\hline $\begin{array}{l}\text { The equivalent radius for a rectangle of dimensions } \\
2 b \times 2 l \text { in torsional vibrations }\end{array}$ & $r_{0}=\sqrt[4]{\frac{16 b l^{3}}{3 \pi}}$ & $\mathrm{m}$ & $\begin{array}{l}\text { Whitman and } \\
\text { Richart }[16]\end{array}$ \\
\hline The vertical frictional spring constant & $K_{s v}=k_{j} K_{h}$ & $\mathrm{~N} / \mathrm{m}$ & \\
\hline The horizontal frictional spring constant & $K_{s h}=k_{i} K_{v}$ & $\mathrm{~N} / \mathrm{m}$ & \\
\hline The vertical coulomb damping constant & $C_{s v}=c_{j} C_{h}$ & $\mathrm{~N} / \mathrm{m}$ & \\
\hline The horizontal coulomb damping constant & $C_{s h}=c_{i} C_{v}$ & $\mathrm{~N} / \mathrm{m}$ & \\
\hline
\end{tabular}

where subscripts " $i "$ and " $j "$ refer to the row and column numbers for the position of the specific elements in the corresponding matrices.

The other elements of matrix $K_{x s}$ are equal to zero. Matrices $K_{x s b}$ and $K_{x b s}$ represent interaction of the soil and building elements, respectively. In these matrices, connections are only through the foundation. The other elements corresponding to the different floors of the building do not have direct connection with the soil. Matrix $K_{y s}$ is for the elastic half space in vertical " $y$ " direction:

$$
K_{y s}(p, p)= \begin{cases}K_{v}+2 K_{s v} & i=1, \quad j \leq n_{1} \\ & \text { for the 1st row } \\ 2 K_{v}+2 K_{s v} & \end{cases}
$$

The noticeable point is that for those half-space subelements that are in contact with the surface, their vertical stiffness component is as follows:

$$
\begin{aligned}
& K_{y s}(p, p)=K_{v}+K_{C}+2 K_{s v}, \\
& K_{y s}(p, p+1)=-K_{s v}, \\
& K_{y s}(p+1, p)=-K_{s v}, \\
& K_{y s}\left(p, p+n_{j}\right)=-K_{v}, \\
& K_{y s}\left(p+n_{j}, p\right)=-K_{v}, \quad \text { for } \quad i \leq m-1 .
\end{aligned}
$$

The other elements of $K_{y s}$ matrix are nil.

$K_{y t s}$ and $K_{y s t}$ represent the connection between the soil and the track in the vertical direction. Considering the dimensions of the soil elements, assume that " $N$ " is the number of the elastic half-space elements underneath and in direct contact with the railway track. Then, the contact area for the ground surface becomes " $N$ " times the contact area of the soil subelement. As a result, " $N$ " number of elements of $K_{y t s}$ and $K_{y s t}$ matrices will be equal to $\left(-K_{C} / N\right)$. Since the other track elements are not in contact with the soil, the other members of these matrices are equal to zero. As a result of the separation of the displacements in horizontal " $x$ " and vertical " $y$ " directions, the resulting stiffness matrices $K_{y x}$ and $K_{x y}$ are equal to zero. But, when the ground is under vertical excitation, like when a train is passing by, in addition to the vertical acceleration, the lateral acceleration can also be noticed in the building. In fact, the elliptic motion of the Rayleigh wave causes the appearance of the horizontal acceleration in the building. In order to simulate motion of the Rayleigh wave, torsional elements are considered. The connection between the horizontal and vertical " $x$ and $y$ " degrees of freedom with torsional freedom " $\theta$ " is provided by using the frictional elements. In fact, after excitation in the vertical direction, the friction elements assist in transmitting the motion to the rotational degree of freedom. Consequently, the friction elements assist in transmitting the torsional motion into the horizontal direction. 
$K_{\theta s}$ is the torsional stiffness matrix for the soil elements. The elements of this matrix are:

$$
K_{\theta s}(p, p)=\left\{\begin{array}{c}
K_{\theta}+2 K_{s v} l^{2}+K_{s h} b^{2} \\
i=1, \quad j \leq n_{1} \\
\text { for the 1st row of soil } \\
K_{\theta}+2 K_{s v} l^{2}+2 K_{s h} b^{2}
\end{array}\right.
$$

$$
\begin{aligned}
& K_{\theta s}(p, p+1)=-K_{s v} l^{2}, \\
& K_{\theta s}(p+1, p)=-K_{s v} l^{2}, \\
& K_{\theta s}\left(p, p+n_{j}\right)=-K_{s h} b^{2}, \\
& K_{\theta s}\left(p+n_{j}, p\right)=-K_{s h} b^{2}, \quad \text { for } \quad i \leq m-1 .
\end{aligned}
$$

It is assumed that $\tan \theta \approx \theta$.

The other elements of $K_{\theta s}$ matrix are equal to zero. $K_{\theta s b}$ and $K_{\theta b s}$ are the soil and building torsional interaction matrices. In these matrices, only those elements corresponding to the foundation are non-zero. $K_{y \theta}$ is the matrix representing connection between the vertical and torsional degrees of freedom and is calculated according to the following equations:

$$
\begin{aligned}
& K_{y \theta}(p, p)= \begin{cases}l K_{s v} & i=1, \quad j \leq n_{1}, \\
2 l K_{s v} & \text { for the } 1 \text { st row of soil }\end{cases} \\
& K_{y \theta}(p, p+1)=-l K_{s v}, \quad K_{y \theta}(p+1, p)=-l K_{s v} .
\end{aligned}
$$

$K_{x \theta}$ is a matrix representing connection between the horizontal and torsional degrees of freedom.

$$
\begin{aligned}
& K_{x \theta}(p, p)=\left\{\begin{array}{l}
b K_{s h} \quad i=1, \quad j \leq n_{1} \\
2 l K_{s b}
\end{array}\right. \\
& K_{x \theta}\left(p, p+n_{j}\right)=-b K_{s h}, \\
& K_{x \theta}\left(p+n_{j}, p\right)=-b K_{s h} .
\end{aligned}
$$

\subsection{Specifications of the structure in the vicinity of the railway track}

The main objective of this research is the study of the effects of passing trains on the dynamic response of the surrounding structures. Therefore, the dynamic equations for a sample concrete structure with two spans and six floors, as in Figure 1, are included in the modeling processes. The building of interest has a height of $18 \mathrm{~m}$ and width of $12 \mathrm{~m}$. The distance between the track centerline and the building is $20 \mathrm{~m}$. The foundation of this building has a depth of $1.5 \mathrm{~m}$. The modeling of the building consists of frames of beam elements. Each beam element is divided further into two subelements. In order to speed up the solution procedure, further subdividing of the beam elements was avoided. All the elements are of uniform crosssections with the width of $0.3 \mathrm{~m}$ and the thickness of $0.6 \mathrm{~m}$. The lower elements are connected to the elastic half space through the foundation. The properties for the stiffness and damping elements between the foundation and the elastic half space are calculated as the soil-to-soil contact with provisions for a multiplication factor that depends on the material content of the foundation. It needs to be noted that the thickness for the foundation is $0.8 \mathrm{~m}$. The structure modeling is represented by using the beam elements with three degrees of freedom at each node. Such degrees of freedom include the horizontal and vertical displacements and a rotation. The elements are connected to the building foundation and the foundation is connected to the soil. The specifications for the beams and columns of the building model are presented in Table 3 .

The assumption of Rayleigh damping is used in order to calculate the structure damping matrix:

$$
C=\alpha\left\lfloor K_{\text {building }}\right\rfloor+\beta\left\lfloor M_{\text {building }}\right\rfloor .
$$

Constant coefficients $\alpha$ and $\beta$ are equal to:

$$
\alpha=\frac{2 \xi \omega_{1} \omega_{2}}{\omega_{1}+\omega_{2}}, \quad \beta=\frac{2 \xi}{\omega_{1}+\omega_{2}}
$$

$\omega_{1}$ and $\omega_{2}$ are the first and second natural frequencies, and $\xi$ is the structural damping. The recommended value for $\xi$ for steel structures with joints is in the range of 0.03 to 0.07 [30]. $M_{\text {building }}$ is the building mass matrix of dimension $67 \times 67$.

$$
M_{\text {building }}=\operatorname{diag}\left[M_{f} M_{1} \cdots M_{66}\right]
$$

By using the Hermitian cubic shape functions, the stiffness matrix corresponding to a frame element in the structure becomes equal to:

Table 3. Specifications for the beams and columns of the building.

\begin{tabular}{lccc}
\hline Structural element & $\begin{array}{c}\text { Density } \\
\boldsymbol{(}\left(\text { tone } / \mathbf{m}^{\mathbf{3}}\right)\end{array}$ & $\begin{array}{c}\text { Velocity of shear wave } \\
\boldsymbol{V}_{\boldsymbol{s}}(\mathbf{m} / \mathbf{s})\end{array}$ & $\begin{array}{c}\text { The Poison's ratio } \\
\boldsymbol{\nu}\end{array}$ \\
\hline Foundation concrete & 2.50 & 2400 & 0.2 \\
Beams and columns & 2.50 & 2400 & 0.2 \\
\hline
\end{tabular}




$$
\mathbf{k}=\left[\begin{array}{cccccc}
u_{i} & v_{i} & \theta_{i} & u_{j} & v_{j} & \theta_{j} \\
\frac{E A}{L} & 0 & 0 & -\frac{E A}{L} & 0 & 0 \\
0 & \frac{12 E I}{L^{3}} & \frac{6 E I}{L^{2}} & 0 & -\frac{12 E I}{L^{3}} & \frac{6 E I}{L^{2}} \\
0 & \frac{6 E I}{L^{2}} & \frac{4 E I}{L} & 0 & -\frac{6 E I}{L^{2}} & \frac{2 E I}{L} \\
-\frac{E A}{L} & 0 & 0 & \frac{E A}{L} & 0 & 0 \\
0 & -\frac{12 E I}{L^{3}} & -\frac{6 E I}{L^{2}} & 0 & \frac{12 E I}{L^{3}} & -\frac{6 E I}{L^{2}} \\
0 & \frac{6 E I}{L^{2}} & \frac{2 E I}{L} & 0 & -\frac{6 E I}{L^{2}} & \frac{4 E I}{L}
\end{array}\right] .
$$

By using the above matrix that is associated with the individual elements in the structure, matrices $K_{x b}$ $K_{y b}$, and $K_{\theta b}$ are formed representing the building horizontal, vertical, and rotational stiffnesses. Since there is no direct connection between the building and the track, matrices $K_{y t b}$ and $K_{y b t}$ representing the stiffness element between the building and the track in the vertical direction contain elements that are equal to zero. $K_{y s b}$ and $K_{y b s}$ also represent the connection between the soil and the building in the vertical direction. Therefore, only foundation-related elements of these matrices are non-zero. Submatrix $K_{\theta b}$ is also related to the torsional stiffness of the building that contains the rotational components in $\theta$ direction. The above matrices are used later on in order to form the larger matrices for the system.

\subsection{Geometry of the elastic half-space subelements and its boundary conditions}

In the process of solving the system motion equations, the proper choice of the boundary conditions is vital. The boundary conditions need to satisfy the dynamics of the system in a manner that can push the results toward their real values. In order to serve the purpose, it is a good exercise to extend the width and the depth of the subject model to the points on which the effects of the vibration wave propagation can be ignored. When subdividing the elastic half space into its elements and using the concept of the lumped masses, it is also very important to define the dimensions of the subelements. The proper selection of such dimensions has direct effect on the accuracy of the results and the duration of the calculations. For the purposes of this research and through a trial and error procedure, it is found that the dimensions of $1 \mathrm{~m} \times 1 \mathrm{~m} \times 1 \mathrm{~m}$ for the soil subelements are acceptable. The total width and depth of the soil component are $41 \mathrm{~m}$ and $6 \mathrm{~m}$, respectively. Provisions are provided in order to stop the reflection of vibration waves at the model boundaries. This is achieved by increasing the amount of damping and stiffness coefficients for all the elements at the boundaries of the elastic half-space model in the horizontal and vertical directions [23]. The conditions applied to the boundaries are presented in Figure 3. It is important to notice that adding to the number and the sizes of the subelements severely increases the total computation time. On the other hand, reducing the number of such elements increases the possibility for the vibration waves returning into the model. Such effect can clearly be observed on the dynamic response of the individual elements. Therefore, the proper choice of the properties of such elements has major effect on the solution procedures.

\subsection{Dynamic loading of the track by the moving train}

The track dynamic loading depends on the geometry of the train, the axle load, and the vehicle's speed of travel. The loading is periodic and happens at the wheel/rail interface with a scenario that is mathematically described in Eq. (29) and is schematically presented in Figure 5:

$$
f(t)= \begin{cases}F_{1} & 0<t<t_{1} \\ 0 & t_{1}<t<t_{2} \\ F_{1} & t_{2}<t<t_{3} \\ 0 & t_{3}<t<t_{4}\end{cases}
$$

\section{The motion equations and the solution procedure}

All the matrices presented in the previous sections of this article need to be assembled in order to reach their global forms. The mass and moment of inertia matrices are presented in Eq. (30):

$$
M_{\text {total }}=\operatorname{diag}\left[M_{x} M_{y} J\right] .
$$

Submatrix $M_{x}$ is the effective mass in horizontal " $x$ " direction, $M_{y}$ contains the effective masses in vertical " $y$ " direction, and " $J$ " holds the moment of inertia for the soil elements that have rotational degrees of freedom:

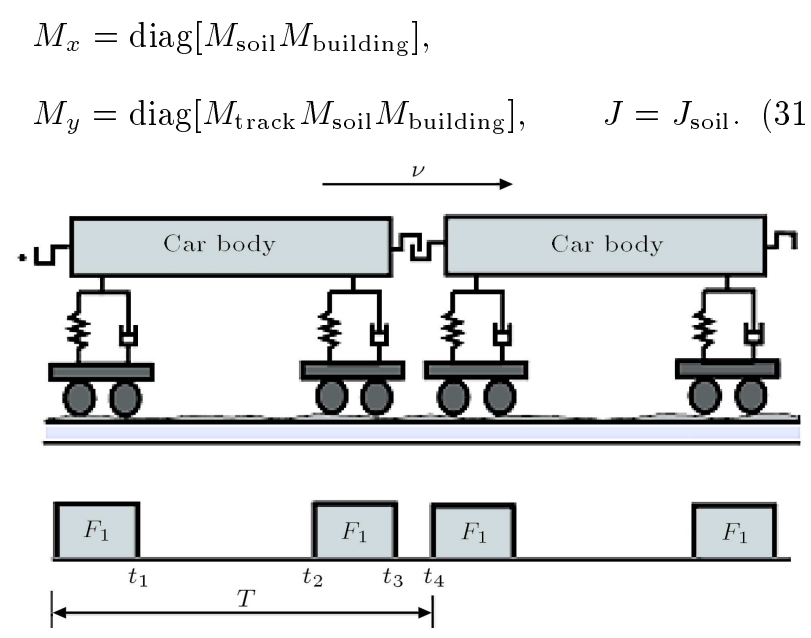

Figure 5. Dynamic loading of the track by the railway vehicle. 
The system stiffness matrix is calculated according to Eq. (32):

$$
K_{\text {total }}=\left[\begin{array}{lll}
K_{x x} & K_{x y} & K_{x \theta} \\
K_{y x} & K_{y y} & K_{y \theta} \\
K_{\theta x} & K_{\theta y} & K_{\theta \theta}
\end{array}\right]
$$

In this matrix, $K_{x x}$ is the system stiffness along horizontal " $x$ " axis. Submatrix $K_{x x}$ contains two main components that relate to the building and the ground bed. The track does not hold degree of freedom along horizontal " $x$ " axis. Submatrix $K_{y y}$ represents stiffness along vertical " $y$ " axis. It contains components corresponding to the building, the soil, and the track. The next submatrix is $K_{\theta \theta}$ and represents the torsional stiffness. It holds torsional stiffness for the building and the soil and is of the following form:

$$
\begin{aligned}
K_{x x} & =\left[\begin{array}{ll}
K_{x s} & K_{x s b} \\
K_{x b s} & K_{x b}
\end{array}\right], \\
K_{y y} & =\left[\begin{array}{lll}
K_{y t} & K_{y t s} & K_{y b b} \\
K_{y s t} & K_{y s} & K_{y s b} \\
K_{y b t} & K_{y b s} & K_{y b}
\end{array}\right], \\
K_{\theta \theta} & =\left[\begin{array}{ll}
K_{\theta s} & K_{\theta s b} \\
K_{\theta b s} & K_{\theta b}
\end{array}\right] .
\end{aligned}
$$

Matrices $K_{\theta x}$ and $K_{\theta y}$ are according to Eq. (34):

$$
K_{x \theta}^{T}=K_{\theta x}, \quad K_{y \theta}^{T}=K_{\theta y} .
$$

The procedure for calculating the global damping matrix, $C_{\text {total }}$, is the same as calculating the global stiffness matrix. However, in this case, the damping elements are calculated instead of the stiffness components:

$$
C_{\text {total }}=\left[\begin{array}{lll}
C_{x x} & C_{x y} & C_{x \theta} \\
C_{y x} & C_{y y} & C_{y \theta} \\
C_{\theta x} & C_{\theta y} & C_{\theta \theta}
\end{array}\right]
$$

Eventually, the motion equations take the following form:

$$
\left[M_{\text {total }}\right] \ddot{x}+\left[C_{\text {total }}\right] \dot{x}+\left[K_{\text {total }}\right] x=F,
$$

where " $F$ " represents excitation. In order to solve the above set of motion equations, a MATLAB-based computer program is written. This program uses the Runge-Kutta method to solve the set of differential equations [31]. The corresponding program flowchart is given in Figure 6. The program output is the system's dynamic response in the form of the particle displacement, velocity, and acceleration at its degrees of freedom.

\section{Verification of the proposed numerical method}

At this stage, it is needed to verify the adequacy of the proposed discrete mass model in predicting the dynamic behavior of the structures in the vicinity of the railway tracks. This is performed by comparing its output with the results that have already been reported by some other researchers. Three examples are selected. The first example is the study of the reduction in the vibrations by increasing the distance away from the track. It is also concerned with analyzing the model behavior at its different degrees of freedom. The second example involves studying the effect of the moving load pass by frequency on the ground response. The third example involves the study of the effects of the propagated vibration waves on the structures in the vicinity of the railway tracks.

\subsection{The first example: Study on the effect of the distance from the track on reducing the vibration levels}

In order to validate the accuracy of the modeling method in predicting the dynamic response at different distances from the railway track, the results are compared with those from FTA-VA-90-1003-06 standard document [4]. FTA standard includes the results of a combination of tests involved with measuring the ground vibrations caused by different passing trains at a variety of distances from the track. The fleet speed of travel is $80.5 \mathrm{~km} / \mathrm{h}$. FTA tests involved a variety of trains including the freight and the passenger trains with or without the traction units. Some Light Rail Vehicles (LRV) are also covered. The model includes the parts with dimensions presented in Figure 3. A slight variation is that in this case, the structure is removed from the modeling. Therefore, it includes the track and the elastic half space, only. Consequently, the dynamic matrix of the system does not contain the components representing the structure. Dimensions of the soil subelements are defined as $1 \mathrm{~m} \times 1 \mathrm{~m} \times 1 \mathrm{~m}$. In this case, a passenger train and a freight train are presented with maximum axle loads of $3.924 \mathrm{e} 4 \mathrm{~N}$ and $5.15 \mathrm{e} 4 \mathrm{~N}$ travel over the track. The sample rolling stock includes a tanker freight train and a passenger train. The geometrical properties and the axle load for such trains in the loaded and unloaded conditions are presented in Table 4. The comparisons between the results of FTA standard and those of the proposed discrete mass model are presented in Figure 7 .

The distance between the desired test point and the track centerline is in the range of (3.05-91.45 m). The Root Mean Square (RMS) of the particle velocity level is calculated according to Eq. (37) presented in 


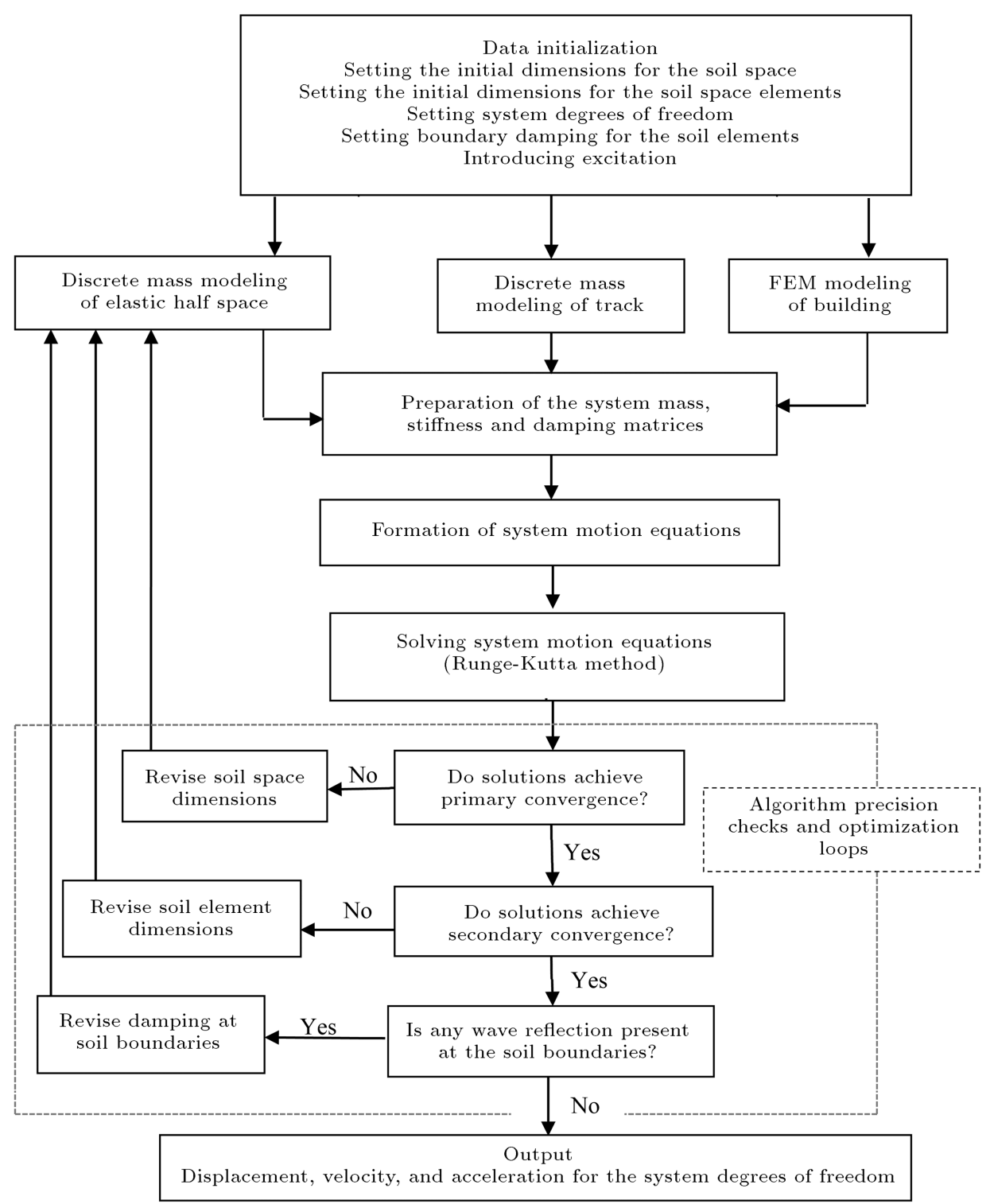

Figure 6. The program flowchart for the proposed discrete mass modeling.

Table 4. The properties of the freight train and the passenger train.

\begin{tabular}{cccc}
\hline The property & Unit & $\begin{array}{c}\text { Freight } \\
\text { train }\end{array}$ & $\begin{array}{c}\text { Passenger } \\
\text { train }\end{array}$ \\
\hline$L$ & $\mathrm{~mm}$ & 11960 & 26000 \\
$d$ & $\mathrm{~mm}$ & 3300 & 5500 \\
$x$ & $\mathrm{~mm}$ & 1500 & 2500 \\
$F_{1}$ (unloaded) & $\mathrm{N}$ & $1.4715 \mathrm{e} 4$ & $3.433 \mathrm{e} 4$ \\
$F_{1}$ (loaded) & $\mathrm{N}$ & $5.150 \mathrm{e} 4$ & $3.924 \mathrm{e} 4$ \\
\hline
\end{tabular}

Figure 7:

$$
L_{V}=20 \log _{10} \frac{V}{V_{\text {ref }}},
$$

where " $V$ " is the RMS of the particle velocity, and $V_{\text {ref }}$ is the particle reference velocity.

According to the US standards, the particle reference velocity is equal to $V_{\text {ref }}=2.54 \mathrm{e}-4 \mathrm{~m} / \mathrm{s}$ [4]. Pa- rameter " $V$ " represents the level of ground vibrations in decibel units $(\mathrm{dB})$. In Figure 7 , the horizontal axis presents the distance between the oscillating particle (on the ground surface) and the track centerline in a logarithmic scale.

It is noticeable that the amplitude and trend in the reduction of the RMS of the particle velocity with increasing distance that are predicted by the proposed discrete mass model are comparable to the results reported in [4].

\subsection{The second example: The effect of the loading frequency on the ground response}

This case is with the assumption of a uniform elastic half space and a track foundation of different material content. A load of magnitude, $P_{o}=1 \mathrm{kN}$, in the form of a harmonic wave, $P=P_{o} e^{i \omega t}$, is applied to the track foundation. It causes oscillations of the circumferential 


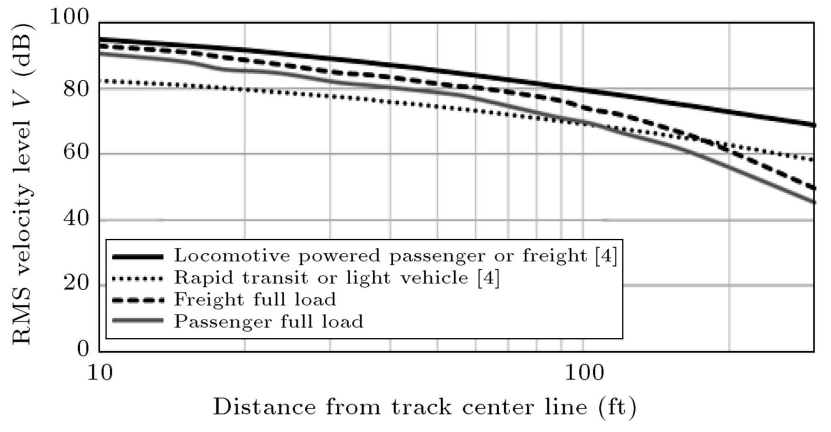

Figure 7. RMS of the particle velocity against the distance from the track centerline; a comparison between the predictions by the proposed discrete mass model and the FTA standard [4].

particles in the elastic half space. The effect of different loading frequencies on the behavior of the vibrating particles is determined at point $x=5 \mathrm{~m}$ measured from the track centerline. Yang and Hung [32] presented the results for the velocity and acceleration at $x=$ $5 \mathrm{~m}$ based on the finite-element modeling. The track foundation is $3 \mathrm{~m}$ in length and $0.5 \mathrm{~m}$ in height. When comparing the results, it needs to be reminded that the finite-element model in [32] considers smaller sizes of meshes for the elements on the surface. Table 5 provides the specifics of the elastic half space and the track foundation for this case.

In order to compare the results with those of the proposed discrete mass model, the model configuration is set according to Figure 3. As in the first example, the model does not include the structure. The output data are for an element on the ground surface that coincides with point " $x$ " that is $5 \mathrm{~m}$ away from the

Table 5. The soil and the track foundation dynamic specifications.

\begin{tabular}{lcccc}
\hline \multicolumn{1}{c}{ Layer } & $\begin{array}{c}\boldsymbol{\rho} \\
\left(\mathbf{k g} / \mathbf{m}^{\mathbf{3}}\right)\end{array}$ & $\begin{array}{c}\boldsymbol{E} \\
(\mathbf{M P a})\end{array}$ & $\boldsymbol{\nu}$ & $\begin{array}{c}\boldsymbol{\beta} \\
(\boldsymbol{\%})\end{array}$ \\
\hline Soil & 1800 & 46 & 0.33 & 5 \\
Track bed & 2400 & 13800 & 0.33 & 2 \\
\hline
\end{tabular}

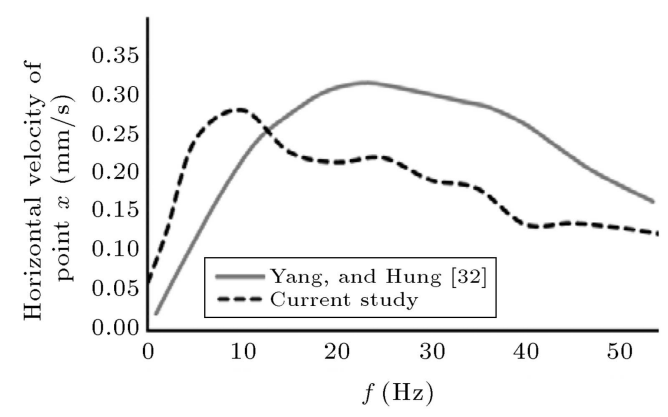

(a) track centerline. In the proposed discrete mass method, reduction in the sizes of the subelements improves the results and convergence of the two methods. However, reduction in the sizes of the subelements severely increases the total number of the degrees of freedom and elongates the solution time. It can then occupy loads of computer memory spaces. It is concluded that subelements of sizes $0.5 \mathrm{~m} \times 0.5 \mathrm{~m}$ are appropriate. The horizontal component of the particle velocity at point " $x$ " against different loading frequencies is presented in Figure 8(a). At lower frequencies, the particle speed increases, while it decreases at higher frequencies. Compatibility between the results of the proposed discrete mass model and the FEM model is acceptable for the amplitude and the trend in the horizontal component of the particle velocity. The trend for the horizontal component of the particle acceleration at point " $x$ " is presented in Figure $8(\mathrm{~b})$. The particle acceleration rises till the frequency of $40 \mathrm{~Hz}$ and decreases afterward.

The vertical components of the particle velocity and acceleration at point " $x$ " are presented in Figure $9(\mathrm{a})$ and (b), respectively.

The same as the horizontal component of the velocity, the vertical component of the particle velocity (for a particle on the surface) initially increases and decreases afterwards. There is good compatibility for the amplitude, and the trends in the predictions by the two methods are fairly similar. The trend for the vertical component of the acceleration presented in Figure 9(b) is also the same. With increasing loading frequency, the particle acceleration also increases.

In this set of results, both methods work based on numerical solutions. For the purposes of the present research, smaller optimized sizes for the soil elements are used. Therefore, it is expected for the results to aptly converge to the real case. However, such optimized cell dimensions and the considerably higher degrees of freedom face computation time limits. The fluctuations noted in the results are attributed to such limitations.

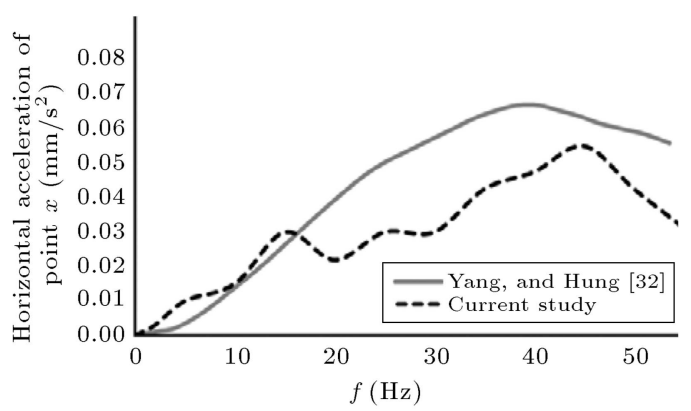

(b)

Figure 8. Variations of the horizontal component of (a) particle velocity and (b) particle acceleration, at point $x=5 \mathrm{~m}$ with increasing loading frequency. 


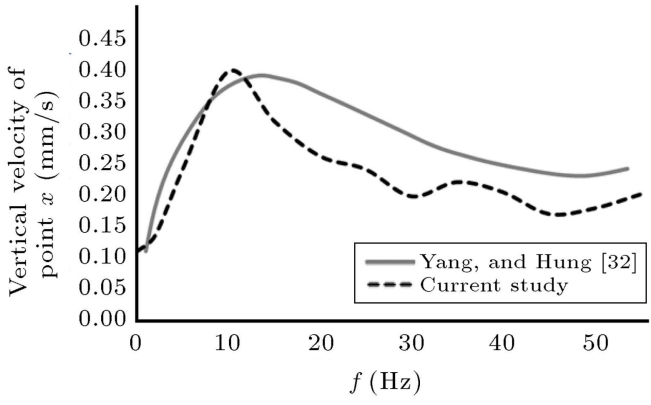

(a)

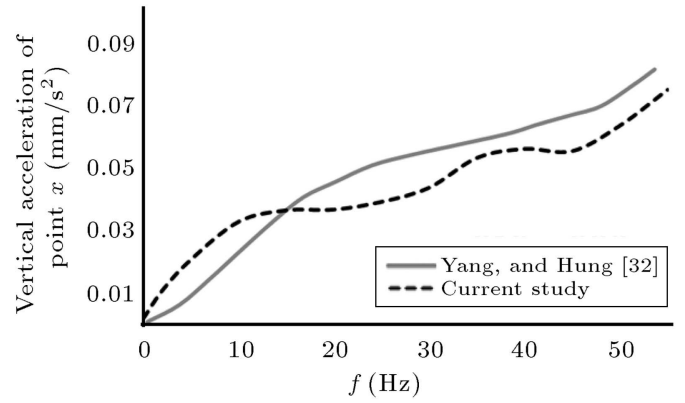

(b)

Figure 9. Variations of the vertical component of (a) particle velocity and (b) acceleration, at point $x=5$ mith increasing loading frequency.

\subsection{The third example: The effect of vibration propagation on the nearby structure}

It is assumed that a building consisting of 6 floors with the width of $12 \mathrm{~m}$ and the height of $18 \mathrm{~m}$ is located at a distance of $20 \mathrm{~m}$ away from the track centerline. The structure foundation extends $0.8 \mathrm{~m}$ in the ground. From the dynamic analysis, the calculated natural frequencies of the structure are equal to $\omega_{1}=$ $2.9 \mathrm{rad} / \mathrm{sec}$ and $\omega_{2}=9.1 \mathrm{rad} / \mathrm{sec}$. Further specifications of this structure can be found in Table 3. Adam and Estroff [33] considered such a building together with a cross-section of the railway embankment, the underlying soil, and the elastic half space in their model. They studied the dynamic response of this structure under the effect of loading by considering four step functions at equal intervals and periods of $0.04 \mathrm{sec}$. The amplitude of the assumed load is $P=1000 \mathrm{kN} / \mathrm{m}$. It is applied on two points to represent the act of two wheels on the track surface. The simulation by Adam and Estroff [33] was based on the continuous mass modeling. It was based on a combination of the finite element and boundary element methods. The overlapping of the structure and soil was completely considered in this modeling. The proposed discrete mass model corresponding to this case is the same as the one in Figure 3. Specifications of the parts of this system are presented in Table 6 .

A comparison for the particle acceleration at test point "A" on the sixth floor under step loading that are predicted by using the proposed discrete mass

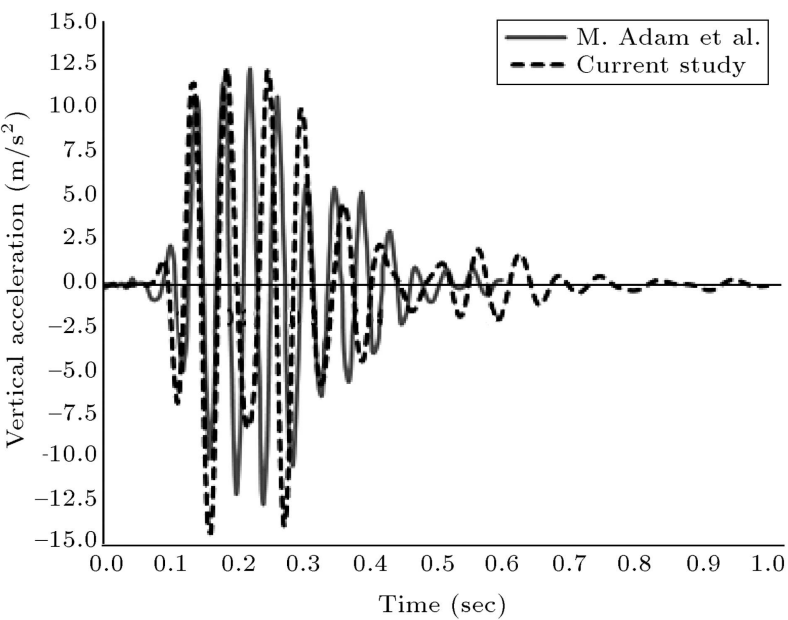

Figure 10. Vertical acceleration of point A on the 6th floor, predictions by the proposed discrete mass model and the FEM model [33].

model and the FEM model is provided in Figure 10. The number of the peaks in the dynamic response, amplitude, and acceleration attenuation predicted by the two methods is highly compatible.

\section{Sensitivity analysis in the dynamic response of a structure}

Versatility of the proposed discrete mass model in predicting the dynamic response of the points inside the elastic half space and on the structure under the

Table 6. Properties of the material content of the system.

\begin{tabular}{lccc}
\hline \multicolumn{1}{c}{ Material } & $\begin{array}{c}\text { Density } \\
\boldsymbol{\rho}\left(\mathbf{T o n} / \mathbf{m}^{\mathbf{3}}\right)\end{array}$ & $\begin{array}{c}\text { Velocity of the } \\
\text { shear wave } \\
\boldsymbol{V}_{\boldsymbol{s}}(\mathbf{m} / \mathbf{s})\end{array}$ & $\begin{array}{c}\text { Variable index } \\
\boldsymbol{\nu}(-)\end{array}$ \\
\hline $\begin{array}{l}\text { Elastic half space } \\
\text { Ground }\end{array}$ & 2.00 & 150 & 0.33 \\
& 2.00 & 250 & 0.33 \\
Mixture of soil & Variable & Variable & Variable \\
and betonite & $(1.2,1.6,2.0)$ & $(30,60,90)$ & $(0.25,0.33,0.45)$ \\
\hline
\end{tabular}


effect of loading by moving trains is already established in the prior sections of this article. In this section, it is intended to further analyze the behavior of the structures in the vicinity of the railway tracks. One way to perform this is by allowing the same fleet under variety of axle loads and at different speeds to travel along the track. The sensitivity in the dynamic response of the particles in the elastic half space and on the structure to a variety of loading conditions is checked. The numerical test includes a freight train and a passenger train which was tested 4 times, each time carrying different axle loads. The data corresponding to the fleet are the same as those in Table 4. Both loaded and unloaded conditions of the trains are investigated. The domain of the operational speed for the passenger train is $25-45 \mathrm{~m} / \mathrm{s}$ and for the freight train is $10-25 \mathrm{~m} / \mathrm{s}$. The speed intervals of $5 \mathrm{~m} / \mathrm{s}$ are considered for the sensitivity analyses. By considering the dimensions of the model and its associated elements, the system holds 876 degrees of freedom. The results of the analyses include the vertical components of the particle displacement, velocity, and acceleration. The particle velocity is also presented in decibel $(\mathrm{dB})$ units to make it compatible with the FTA standard recommendations. The peak values for such data are further processed and put together to form the output with the desired shapes. The points of interest in the calculations include points $\mathrm{A}, \mathrm{B}, \mathrm{C}, \mathrm{D}, \mathrm{E}, \mathrm{F}$ that represent locations on floors 1 to 6 in the building, respectively. The building is assumed to be located in the vicinity of a railway track (Figure 1). The depth of the model in the ground is $6 \mathrm{~m}$ and the distance between the building and the track centerline is $20 \mathrm{~m}$ as in Figure 1 . The selected dimensions of the soil elements are $1 \mathrm{~m} \times 1 \mathrm{~m} \times 1 \mathrm{~m}$. The specifications of the track elements, the building, and the soil are the same as in Tables 2, 3, and 6, respectively.

\subsection{The numerical tests}

The numerical tests involve calculation of the dynamic response in the form of the Peak Particle Displacement (PPD), Velocity (PPV), and Acceleration (PPA) while varying the fleet speed of travel. A sample output from the computer program for the case of a loaded freight train, with data from Table 4, is presented in Figure 11. It is assumed that the train speed of travel is $25 \mathrm{~m} / \mathrm{s}$. This figure presents the vertical acceleration of point $\mathrm{E}$ in the building. The effect of the spacing between the bogies on the vehicles can clearly be noticed in this figure.

The sensitivity analysis reported in the later sections of this article involves finding and putting together the peak values in the particle displacement, velocity, and acceleration results. Naturally, it contains an enormous number of calculations. The behavior

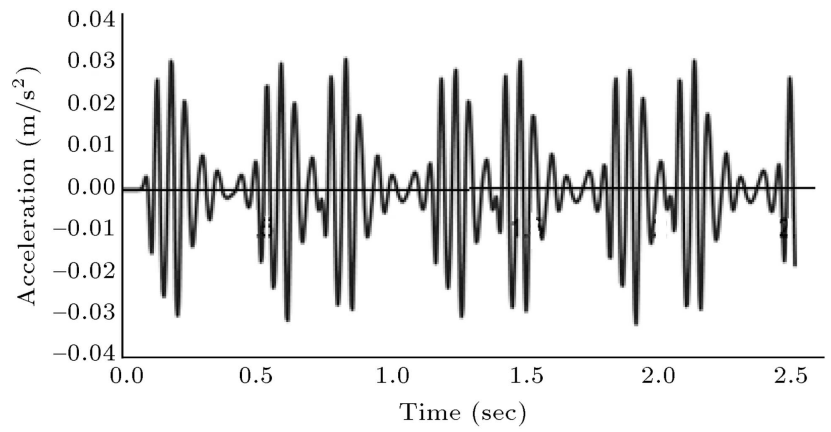

Figure 11. The response of point $\mathrm{E}$ in the building due to a train passing at maximum axle load.

of the structure and the performance of its damping are also investigated. Damping in the structure causes dissipation of the mechanical energy. It is caused by the friction in the building material that is generated during the wave propagation.

It transforms the mechanical energy into the thermal energy. Such damping is a property of the building material and increases with the increase in the speed and frequency of the wave propagation [34].

\subsection{Response of the structure due to the passing of an unloaded passenger train}

The response of the structure due to the passing of a passenger train with the minimum axle load of $3.43 \mathrm{e} 4 \mathrm{~N}$ is investigated. As a result, the displacements at levels 1 to 6 of the building at the selected points are presented in Figure 12(a). It is shown that the displacement reaches its peak value of $2.75 \mathrm{e}-6 \mathrm{~m}$ at the 6 th floor when the speed of travel of the passing train is equal to $30 \mathrm{~m} / \mathrm{s}$ and drops afterward. The same trend can be observed in the velocity curve in Figure 12(b). The data in Figure 12(b) are in decibel units. The Peak Particle Velocity (PPV) in this case is $88.78 \mathrm{~dB}$. It can be used in conjunction with Eq. (37) and the recommendations by the FTA in order to calculate the level of vibration annoyance. Contrary to the trend in the particle displacement and velocity data, the particle acceleration decreases when the fleet speed of travel increases (Figure 12(c)). The reduction in the level of vibration from the 6 th floor to the 1 st floor has obvious non-linear behavior. The ratio of increase in the maximum particle displacement from the 1 st to the 6 th floor is $21 \%$.

\subsection{Response of the structure due to the passing of a loaded passenger train}

In this case, it is assumed that a loaded passenger train at its maximum axle load passes nearby a structure. Variations in the displacement and velocity $(\mathrm{dB})$ at the selected points in the structure are given in Figure 13(a) and (b), respectively. In each case, the initial trend is on the rise in the displacement and velocity of points and on the decline afterward. However, 


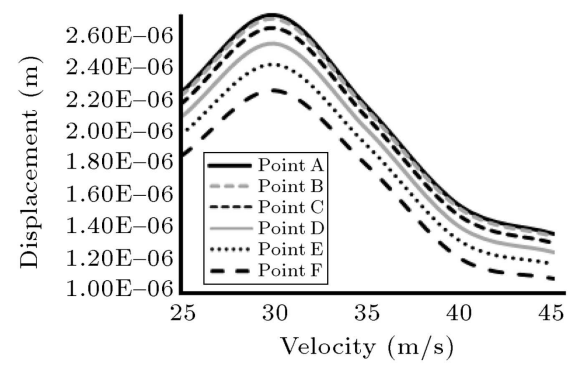

(a)

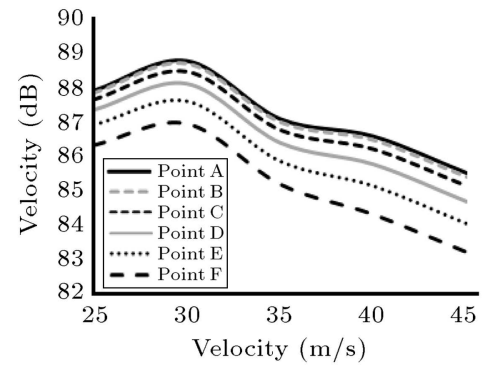

(b)

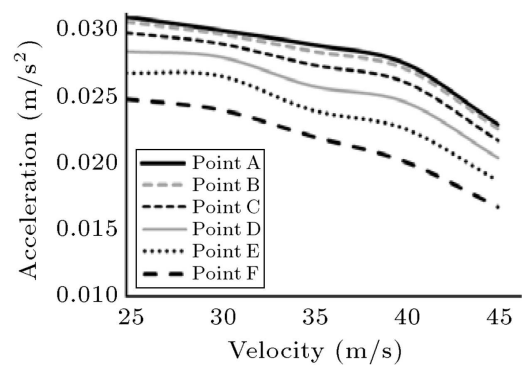

(c)

Figure 12. Maximum displacement (a), velocity (b), and acceleration (c) at the selected points in floors 1-6 of the building due to the passing of an unloaded passenger train.

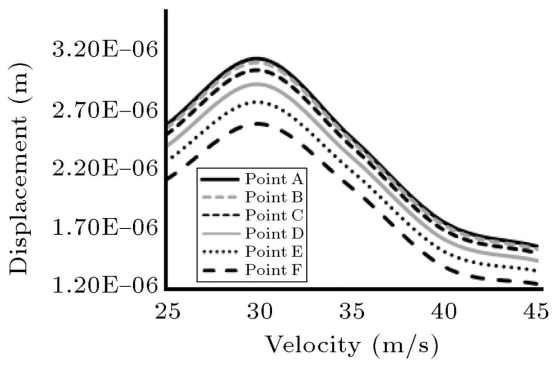

(a)

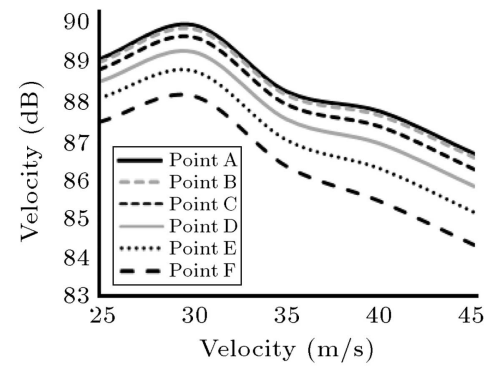

(b)

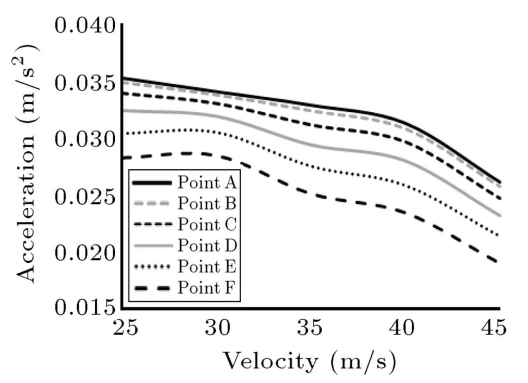

(c)

Figure 13. Maximum displacement (a), velocity (b), and acceleration (c) at the selected points in the floors 1-6 of the building due to the passing of a loaded passenger train.

the decrease in the displacement is sharper than the decrease in the velocity and starts later after the speed of $45 \mathrm{~m} / \mathrm{s}$. The maximum displacement happens at the 6 th floor. It is equal to $3.14 \mathrm{e}-6 \mathrm{~m}$ and happens when the fleet speed of travel is equal to $30 \mathrm{~m} / \mathrm{s}$. The maximum displacement in the 6th floor is $20.8 \%$ higher than the 1 st floor. The maximum calculated Peak Particle Velocity (PPV) is equal to $89.94 \mathrm{~dB}$. Variations in the acceleration of the selected points in the structure are presented in Figure 13(c). All points exhibit decreasing behavior in the calculated accelerations. Comparison between the results in the last two sections related to the unloaded and loaded passenger trains proves that by increasing the axle load from the minimum to the maximum value, there is a rise of about $15 \%$ in the levels of vibration at the selected points in the structure.

\subsection{Response of the structure due to the passing of an unloaded freight train}

The major difference between the freight and the passenger trains is that the bogie length and the vehicle length are normally shorter for the freight cars. Therefore, this changes the frequency of track loading with the freight trains. By using the data from Table 4 , variations in the displacement of the selected points in the building in the vicinity of the railway track are presented in Figure 14(a). There is an obvious reduction in the particle displacements after $20 \mathrm{~m} / \mathrm{s}$ travel speed. The maximum displacement is equal to 9.72e- $7 \mathrm{~m}$ and happens at point $\mathrm{F}$ on the 6 th floor. There is $22.5 \%$ difference between the displacement of points $\mathrm{A}$ and $\mathrm{F}$ on the 1 st and the 6 th floors. Variations of the particle velocity $(\mathrm{dB})$ at the selected points on different floors are presented in Figure 14(b).

This figure holds a peak when the fleet speed of travel is equal to $15 \mathrm{~m} / \mathrm{s}$. The peak particle velocity is equal to $80.52 \mathrm{~dB}$. Contrary to the case of the passenger train that the acceleration kept decreasing at the operational speed, in case of the freight train, acceleration initially increases and decreases later on (Figure 14(c)).

\subsection{Response of the structure due to the passing of a loaded freight train}

This case involves the passing of a freight train at its maximum axle load. Of interest is the response of a building in the vicinity of the track. There are six selected points on different levels in the building monitored for their dynamic responses. Variations of the displacement of the selected points against the speed of travel of the fleet are presented in Figure 15(a). There are slight variations with decreasing effect in the displacements of the points at the lower speed of travel. Such variations in the displacements are much sharper when the speed of travel of the fleet increases to its higher values. It has already been mentioned that by increasing the vehicle speed of travel, damping in the structure increases. The maximum displacement is equal to $3.4 \mathrm{e}-6 \mathrm{~m}$ and the difference in displacement 


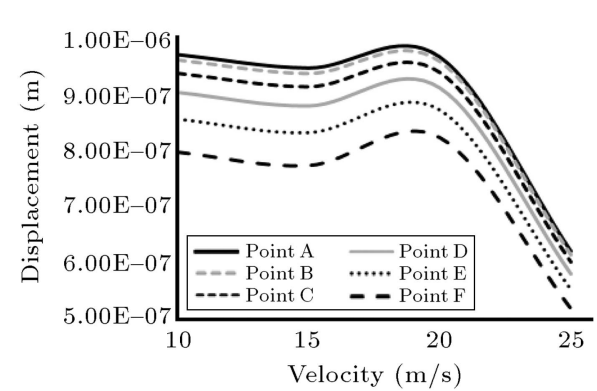

(a)

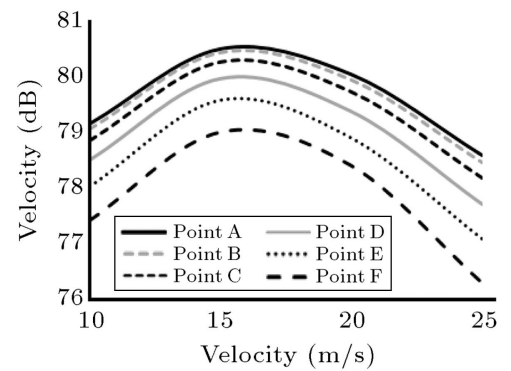

(b)

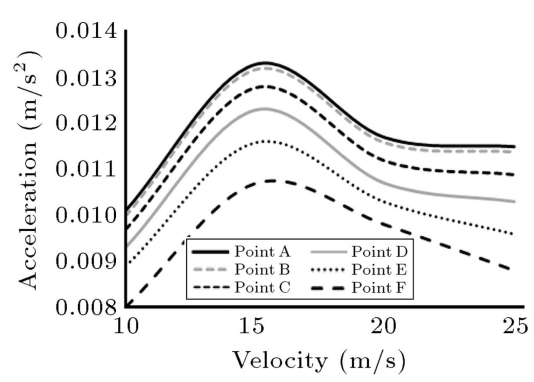

(c)

Figure 14. Maximum displacement (a), velocity (b), and acceleration (c) at the selected points in floors 1-6 of the building due to the passing of an unloaded freight train.

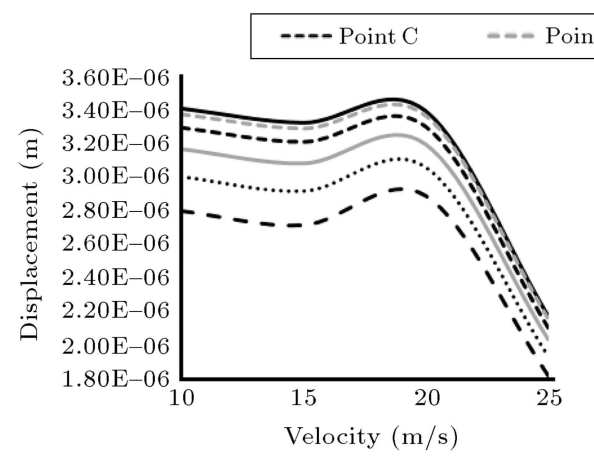

(a)

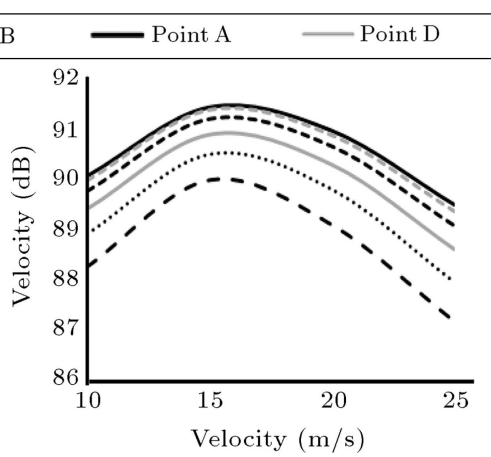

(b)

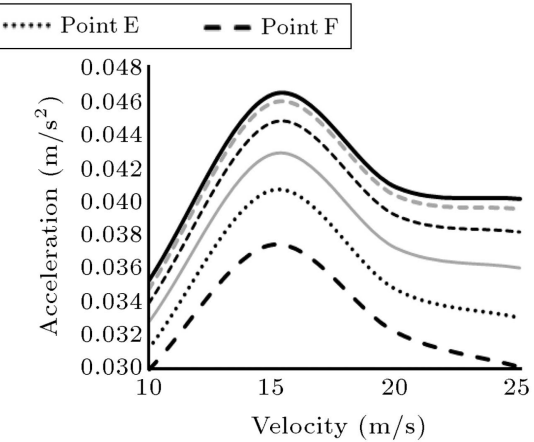

(c)

Figure 15. Maximum displacement (a), velocity (b), and acceleration (c) at the selected points in floors 1-6 of the building due to the passing of a loaded freight train.

between the 1st and the 6th floors is $17 \%$. By increasing the fleet speed of travel up to $15 \mathrm{~m} / \mathrm{s}$, the particle velocity at the selected points also increases (Figure 15(b)).

However, it drops after the speed of $15 \mathrm{~m} / \mathrm{s}$. For the particle acceleration at the selected points, it is noticeable that the variations in the acceleration are mild at the higher operating speed. Also, the rate in the decrease of the acceleration is higher at the lower floors (Figure 15(c)). The peak particle velocity is equal to $91.4 \mathrm{~dB}$ and happens at point $\mathrm{F}$ on the 6 th floor. For the cases considered here, the levels of vibrations are 3.5 times higher with the loaded freight train compared with the unloaded one. Also, the difference in the axle load between the passenger train and the freight train, both in their loaded case, causes $10 \%$ difference in the levels of vibrations.

It is noticeable that Figures 14 and 15 corresponding to the cases of unloaded and loaded freight trains contain the same trend for the variations in the particle displacement, velocity, and acceleration. Such a trend is due to the high frequency of loading for these cases. On the other hand, Figures 12 and 13 that correspond to the cases of unloaded and loaded passenger trains with lower loading frequencies contain the same trend that can be different from the cases of freight trains.

\section{Conclusions}

The aim of this research is to investigate the dynamic response of the structures in the vicinity of railway tracks. The passing rolling stocks loaded the railway tracks through the wheel/rail contact points. The underlying ground acts as the transfer medium and propagates the vibration waves toward the nearby structures. The methodology of solution included the assumption of the elastic half space for the transfer medium. Prior researchers in this field considered the elastic half space as a continuous medium and used the concept of the finite-element method for the modeling purposes. This research proposed a discrete mass model for the elastic half space and subdivided this space into many smaller elements that together form a grid of soil elements. This facilitated the inclusion of many degrees of freedom with a variety of stiffness and damping actions happening between the soil subelements. The proposed method facilitates modeling of the track systems that include deliberate discontinuities, such as voids and trenches, in the ground bed that support the railway track. Such discontinuities arise from engineering perception useful in controlling the spread of noise and vibrations. The structure near the railway track was also considered as discrete masses joined together with the concept of the 
finite elements. The dynamic response of the structure at the selected points was obtained. Such responses were presented in the form of the particle displacement, velocity, and acceleration. Variations in such parameters under varying quantities for the distance from the track, different frequency of loading, and different axle loads were tested. The proposed method was verified by comparing its results with those from standard documents and also from those of other researchers in this field. It is concluded that at the higher speed of travel, the increased loading frequency increases the structural damping. The sensitivity analyses for the nearby structure under variety of loaded and unloaded conditions for the passenger and freight trains were tested. The dynamic response of the structure was dependent on the vehicle axle load and its speed of travel. It also depends on the material properties of the structure. The particle velocity data can be used for comparison with annoying vibration levels defined in the corresponding standard documents. Any increase in the axle load increases the level of annoying vibration in the structure. Increase in the axle load pushes the level of vibration in different levels of the structure closer to each other.

While efficient, accurate, and fast, the method presented in this article can be reliably used to estimate the dynamic responses of the structures. These are different kinds of the structures that are under the influence of the vibration waves propagated through the ground layers. It can be used practically in the design and modification processes while the engineers search for remedies to control the levels of unwanted vibrations in the structures.

\section{References}

1. Krylov, V.V. "Generation of ground vibration boom by high speed trains", In Noise and Vibration from High-Speed Trains, V.V. Krylov and T. Telford, Eds., London, pp. 251-283 (2001).

2. Madshu, C. and Kaynia, A.M. "High-speed trains on soft ground: Track-embankment soil response and vibration generation", In Noise and Vibration from High-Speed Trains, V.V. Krylov and T. Telford, Ed., London pp. 315-344 (2001).

3. Jones, S. and Hunt, H. "Voids at the tunnel-soil interface for calculation of ground vibration from underground railways", Journal of Sound and Vibration, 330, pp. 245-270 (2011).

4. Federal Transit Administration "Transit noise and vibration impact assessment", FTA-VA-90-1003-06 (May 2006).

5. British Standards Institution "Guide to evaluation of human exposure to vibration in buildings, (1-80 Hz)", BS 6472 (1992).
6. Mechanical Vibration-Ground-Borne Noise and Vibration Arising from Rail Systems, In ISO148371:2005(en).

7. DIN 4150-3 "Structural vibration. Part 3: Effects of vibration on structures", Deutches Institut für Normung, Berlin, Germany (1999).

8. Mohammadi, M. and Karabalis, D.L. "Dynamic 3-D soil-railway track interaction by BEM-FEM", Earthquake Eng. Struct. Dyn., 24, pp. 1177-1193 (1995).

9. Yang, B.Y. and Hung, H.H. "A 2.5D finite/infinite element approach for modeling visco-elastic bodies subjected to moving loads", Int. J. Numer. Meth. Eng., 240, pp. 1317-1336 (2001).

10. Estorff, O.V., Firuziaan, M., Friedrich, K., Pflanz, G. and Schmid, G. "A 3-dimensional FEM/BEM model for the investigation of railway tracks", Proceedings of the International Workshop Wave 2002, Okayama, Japan, pp. 157-171 (2002).

11. Bode, C., Hirschauer, R. and Savadis, S.A. "Soilstructure interaction in the time domain using halfspace Green's functions", Soil Dyn. Earthquake Eng., 22(4), pp. 283-295 (2002).

12. Adam, M., Pflanz, G. and Schmid, G. "Two and three-dimensional modeling of half-space and train track embankment under dynamic loading", Soil Dyn. Earthquake Eng., 19(8), pp. 559-73 (2000).

13. O'Brien, J. and Rizos, D.C. "A 3D BEM-FEM methodology for simulation of high speed train induced vibrations", Soil Dynamics and Earthquake Engineering, 25, pp. 289-301 (2005).

14. Hall, L. "Simulations and analyses of train-induced ground vibrations in finite element models", Soil Dynamics and Earthquake Engineering, 23, pp. 403-413 (2003).

15. Lysmer, J. and Richart, F.E. "Dynamic response of footings to vertical loading", ASCE J. Soil Mech. Found Div., 92(SM1), pp. 65-91 (1996).

16. Whitman, R.V. and Richart, F.E. Jr. "Design procedure for dynamically loaded foundations", J. Soil Mech. Found. Div., ASCE, 93(SM 6), pp. 169-193 (1967).

17. Wolf, J.P., Foundation Vibration Analysis Using Simple Physical Models, Englewood Cliffs, NJ: PrenticeHall (1994).

18. Wolf, J.P. "Spring-dashpot-mass models for foundation vibrations", Earthquake Eng. Struct. Dyn., 26(9), pp. 931-49 (1997).

19. Jean, W.Y., Lin, T.W. and Penzien, J. "System parameters of soil foundation for time domain dynamic analysis", Earthquake Eng. Struct. Dyn., 19(4), pp. 541-553 (1990). 
20. Wu, W.H. and Chen, C.Y. "Simple lumped-parameter models of foundation using mass-spring-dashpot oscillators", J. Chin Inst. Eng., 24(6), pp. 681-697 (2001).

21. Chen, S.S. and Shi, J.Y. "Simplified model for torsional foundation vibrations", Soil Dynamics and Earthquake Engineering, 27, pp. 250-258 (2007).

22. Chen, S.S. and Shi, J.Y. "A response-based simplified model for vertical vibrations of embedded foundation", Soil Dynamics and Earthquake Engineering, 31, pp. 773-784 (2011).

23. Kuhlemeyer, R.L. and Lysmer, J. "Finite element method accuracy for wave propagation problems", $J$. Soil Mech. \& Foundations, Div. ASCE 99(SM5), pp. 421-427 (1973).

24. Dawn, T.M. and Stanworth, C.G. "Ground vibrations from passing trains", Journal of Sound and Vibration, 66(3), pp. 355-362 (1979).

25. Ahlbeck, D.R., Meacham, H.C. and Prause, R.H. "The development of analytical models for railroad track dynamics", In Railroad Track Mechanics \& Technology, A.D. Kerr, Ed., Pergamon Press, Oxford (1978).

26. Zhai, W.M., Wang, K.Y. and Lin, J.H. "Modeling and experiment of railway ballast vibrations", Journal of Sound and Vibration, 270, pp. 673-683 (2004).

27. Bycroft, G.N. "Forced vibration of a rigid circular plate on a semi-infinite Elastic space and on elastic stratum", Philos. Trans. R. Soc., London. Ser. A, 248, pp. 327-368 (1956).

28. Hall, J.R. Jr. "Coupled rocking and sliding oscillations of rigid circular footings", In Proceedings of the International Symposium on Wave Propagation and Dynamic Properties of Earth Materials, University of New Mexico Press, Albuquerque, pp. 139-148 (1967).

29. Kramer, S.L., Geotechnical Earthquake Engineering, Prentice-Hall International (1996).

30. Cremer, L., Heckl, M. and Petersson, B.A.T., Structure-Borne Sound, Springer Science \& Business Media (2005).

31. Butcher, J.C., Numerical Methods for Ordinary Differential Equations, John Wiley \& Sons, (2003).

32. Yang, Y.B. and Hung, H.H., Wave Propagation for Train-Induced Vibrations, World Scientific Publishing Co., ISBN-13: 978981283582-6 (2009).

33. Adam, M. and Estorff, O.V. "Reduction of traininduced building vibrations by using open and filled trenches", Computers and Structures, 83, pp. 11-24 (2005).
34. Bahrekazemi, M. "Train induced ground vibration and its prediction", PhD. Thesis, Dept. of Civil and Architectural Engineering, Royal Institute of Technology, Stockholm (2004).

\section{Biographies}

Mohammad Ali Rezvani was born in 1960. He holds a PhD degree in Mechanical Engineering from the University of New South Wales in Sydney Australia, 1995. Dr. Rezvani is an academic at the School of Railway Engineering at Iran University of Science and Technology. His areas of expertise include wear and tribology, modal analysis, and control of nonlinear vibrations. Dr. Rezvani is the head of the advanced vibration laboratory at the School of Railway Engineering. The laboratory provides services for the modal testing of the railway infrastructure and rolling stocks. Dr. Rezvani is a member of the national committee for the condition monitoring and fault diagnosis of machineries in Iran.

Morteza Esmaeili is an Associate Professor in Iran University of Science and Technology (IUST). He currently is the director at Railway Track and Structures Department in School of Railway Engineering. His research interest includes static and dynamic behaviors of porous media, underground structures, railway track vibrations and dynamics, and ballastless tracks. Up to now, Dr. Esmaeili has published around 40 journal papers and two books including soil-steel bridges and seismic analysis and design of underground structures. He has also contributed in filing 6 national patents. Dr. Esmaeili cooperates with the editorial board of International Journal Series in Engineering Science, International Journal of Railway Research (IUST Press), and he is the review editor of Transportation and Transit Systems (Frontiers Publication). He is the reviewer of more than 10 journals published by Elsevier, ASCE, ASME, ICE, Springer, KSCE, and IUST.

Mohammad Mahdi Feizi received his BSc and MSc degrees in Rolling Stock Engineering both from Iran University of Science and Technology. His research areas are mainly focused on condition monitoring systems, FSI (Fluid-Solid Interaction), crashworthiness and nonlinear dynamics. He has published several papers in conferences and journals related to mechanical engineering and proceeding in the areas. 